\title{
Development of a smart walking stick for visually impaired people
}

\author{
R. Bhavani a, and S. Ananthakumaran ${ }^{b}$ \\ ${ }^{a}$ Electrical and Electronics Engineering, Mepco Schlenk Engineering College,Sivakasi, Tamilnadu, India. \\ BDepartment of Computer Science and Engineering, Koneru Lakshmaiah Educational Foundation, Andhra Pradesh, India.
}

Article History: Received: 11 January 2021; Accepted: 27 February 2021; Published online: 5 April 2021

\begin{abstract}
One of the major issue faced by blind people are moving from one place to another. Also they get stress while walking along bad conditions of the road. All the time, they are alerted by others to avoid obstacles, staircases and wet terrain. This paper addresses the above issues of blind people with the intervention of technology. Also proffer the development of an electronic stick for blind person to assist them gain self-sufficiency. In the proposed model, an electronic stick was consolidated with an ultrasonic transducer, water circuit and RF transmitter and receiver module. The ultrasonic sensor will sense the obstacle within the span and notify the blind person with the help of buzzer. The water circuit when acquire with the water, it get short circuited and make buzzer to sound. Also, provides a way to find the misplaced stick in indoor. When the person presses the button in the remote, the stick will notify the blind person to realize the stick. Since this is simple, economical and not substantial, one can hold it easily. The prototype model was implemented and the entire setup functions were controlled by using the Arduino ATMEGA 328-PU microcontroller.
\end{abstract}

Keywords: Smart walking stick, obstacle detection, ultrasonic transducer, RF transmitter, RF receiver.

\section{Introduction}

Vision is the vital common sense for humans to stay alive in this world. Blind people always need help from others Moving from one location to another, especially when outdoors. They always need a stick that will support people in their life. Therefore, it is preferable for providing innovative solutions to the complexities of current technology. Existing stick (Gupta, 2015) can guide blind people for finding obstacles through touching. These systems are expensive, have very limited features and unreliable. Lot of researchers focuses for the improvement in the development of blind stick.

The proposed stick (Patil Nagesh Umakant , 2019; Swain, 2017; Aroulanandam, 2020) identifies the obstacles also notify this with vibrations. A stick guide model proposed (Agrawal , 2018; Vaibhav Shah, 2019; Olanrewaju, 2017) includes GPS and GSM module used for sending SMS whenever the person wants to need help. An Arduino based stick (Virendra, 2019; Chinnamahammad bhasha, 2020) which detects the obstacles using Ultrasonic sensors. The blind stick proposed (Rajesh Kannan, 2019) uses ultrasonic and water sensors to identify different obstacles around the distance of about $3 \mathrm{~m}$. A mobile application was developed (Manikanta, 2018; Balamurugan, 2020) using smart phone's camera to aware them regarding obstacles along the path. After recognizing obstacles, the stick notifies the blind people with the help of vibration signals. However the smart blind stick concentrated only on obstacle detection (Jaya Lakshmi , 2019; Balamurugan, 2017; Gayathri, 2014) but it will not support for dangerous aspiration needed by the blind and also, the IR sensors are not enough efficient, because it can detect only the adjacent obstacle in short span. In (Radhika, 2016; Balamurugan, 2020) proposed a Smart blind Walking Stick which defines about a Stick which uses Raspberry Pi controller and an ultrasonic transducer to notify objects and intruder, the system also consist of a camera attached with it, and based on the images captured the objects are identified (Latchoumi, 2020; Pavan, 2020). The objects are analyzed based on the set of images that are already stored. All the studies show that, there are several techniques for designing a walking stick for blind individuals but all are expensive consists of maximum number of datasets is need to be stored.

This work proffers to develop a handy stick designed for easy usage and navigation in public places. Whenever blind people encounter with an obstacle it would notify them by handling buzzer with the assist of ultrasonic sensors. The stick is articulated with another attribute called water circuit. Another endorsed feature of this framework is articulated to assist the blind to locate their stick, if that people fail to recall where they place it. For this, a wireless Radio Frequency established remote is used. This prototype model was implemented using arduino ATMEGA 328 microcontroller. The use of supersonic sensors would be an economical resolution to notice the obstacles with most varies of seven meters and forty five degree coverage.

\section{Proposed system}

The proposed blind stick model presented in Fig. 1 consists of the following components. 


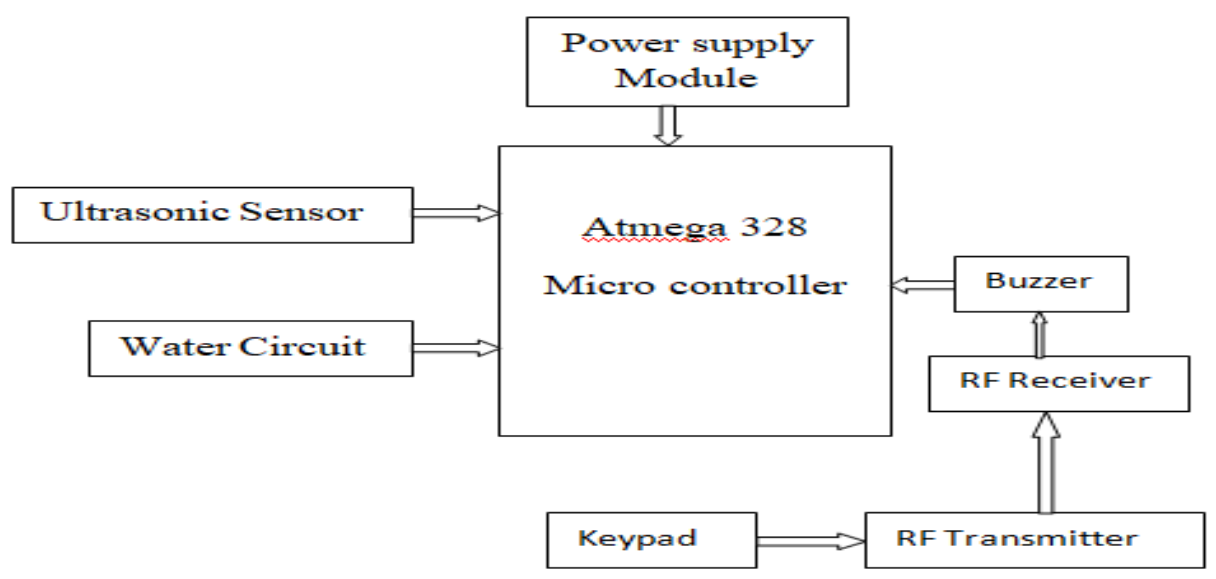

Figure 1. Proposed Blind Stick Model

\subsection{Ultrasonic Sensor module}

Ultrasonic Sensor is used for recognizing the distance of an obstacle from the sensor. In this model HC-SR04 sensor was used. It develops high frequency sound signals from the detected objects. When the sound wave thrashes an object, it will return an echo to the receiver. By estimating the time demand for the waves to gain the receiver the distance can be calculated. The pin configuration and the timing diagram of an ultrasonic sensor are shown in the Fig. 2.

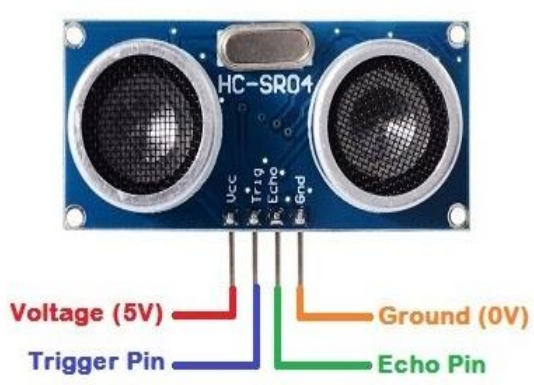

(a)

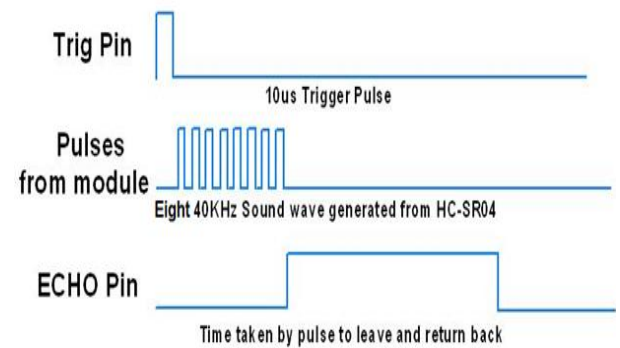

(b)

Figure 2. Ultrasonic sensor circuit a) Pin Configuration b) Timing Diagram

The algorithm makes use of two ultrasonic sensors to detect obstacles. One is located closer to the base of the stick and the other from the bottom end of the stick is positioned at two thirds of the length. This setup can detect barriers of different shapes and sizes. In order to assist the identification of stairs and minor objects on the ground, the IR sensor is placed at the base of the handle.

\subsection{Water Circuit}

The proposed water circuit model shown in Fig. 3 is used to notice the presence of water along the route. Water circuit consist of $5 \mathrm{~V}$ voltage source and $1 \mathrm{M} \Omega$ resistance The resistance $1 \mathrm{M} \Omega$ is connected in series with the source voltage $5 \mathrm{~V}$ and the two probes namely sense probe and ground probe are left free to expose with the water which is used to detect the water. The two probes are allowed to pass the current through the water and then it obtains the resistance measurement to detect the water presence. The voltage across the probe taken as input for comparator based on the sense probe is exposing the water or not. When the sense probe is not exposed with the water, the voltage across probe is $5 \mathrm{~V}$. 


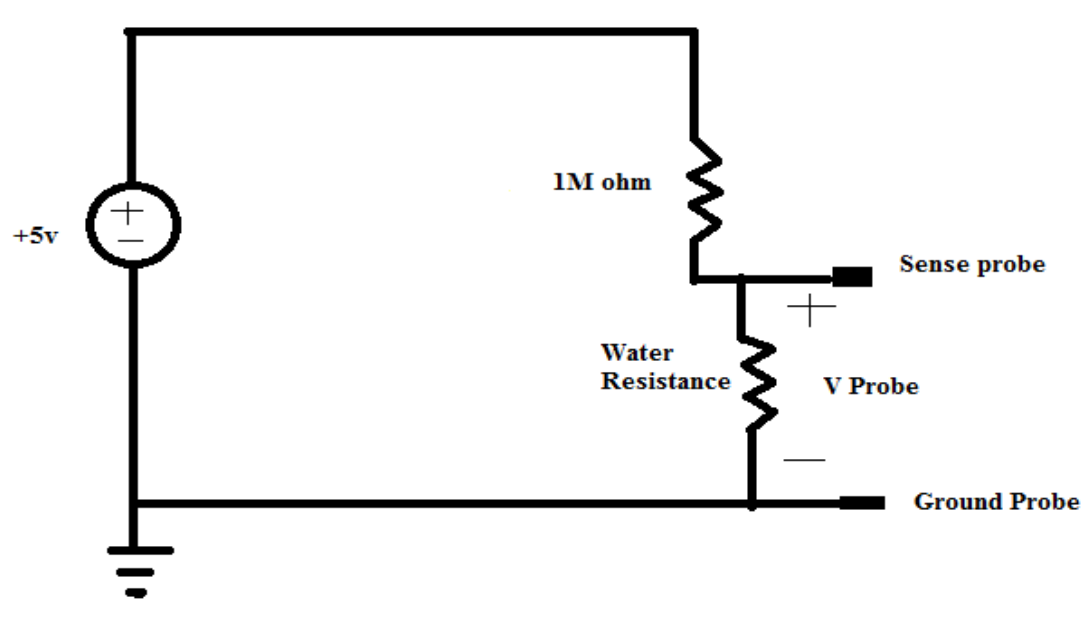

Figure 3. Circuit for detection of water

When the sense probe is exposed with water, the water will behave as a resistance across both the sense and ground probes. If the water is there, the water will conduct greater amount of electricity which indicates the less amount of resistance. Hence, the provided circuit will short circuit to indicate the water presence. If the floor does not have any water it will conducts electricity poorly, which indicates the more amount of resistance.

\subsection{Atmega 328 Microcontroller}

Arduino is open accessible source for hardware and programming applications. This board area unit ready to surf inputs - weightless on a sensing element, a thumb on a push buttons, converts it into an output - driving a motor, switch on a crystal rectifier.

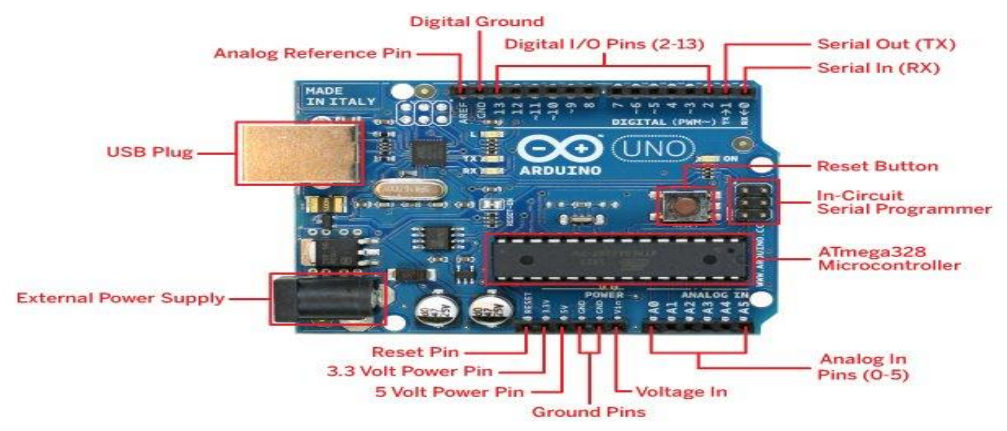

Figure 4. ARDUINO pin description

The biggest value is that it is possible to connect the board to a laptop and a computer, through a USB cable which acts as a twin purpose of supplying power and as a port to interface the Arduino and the computer. The Arduino Uno can be a microcontroller board as well, supported by the ATmega328 microcontroller. It contains twenty digital input and output pins which includes a sixteen megacycle resonator, a USB affiliation, an influence jack, an in-circuit system programming header, and the push button is used. A pin description of the arduino Uno ATMEGA 328-PU microcontroller is shown in Fig. 4. The Arduino Uno consist of 14 digital pin and 6 analog pin. These pins can be used as an input as well as output. Rx pin and Tx pin in an arduino board denote the receiver and transmitter behavior. The ATMEGA328 Microcontroller chip is fixed in the arduino Uno which will do all the controlling application. It consists of two voltage source namely 5volt and 3.3volt.The external voltage within 5volt - 12volt can be given with the assist of Vin pin. The pin number 13 can be used for the LED output which is inbuilt in an Arduino board. The ground pins in the Arduino board is used to ground the circuit.

\subsection{RF Module}

An RF module which is shown in Fig. 5 is composed of a transmitter and receiver for RF. A misplaced stick can be found using this module. Serial data can be transmitted by the RF transmitter. Similarly, an RF receiver can receive this transmitted data. The transmitter is placed on a simple remote control inside this proposed stick. Receiver is located at the top of the stick. 


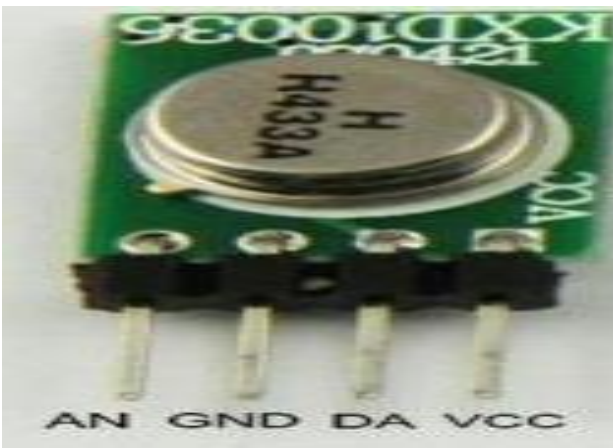

(a)

Figure 4. RF Module

\section{igure 4}

\subsection{Buzzer and the Vibration motor}

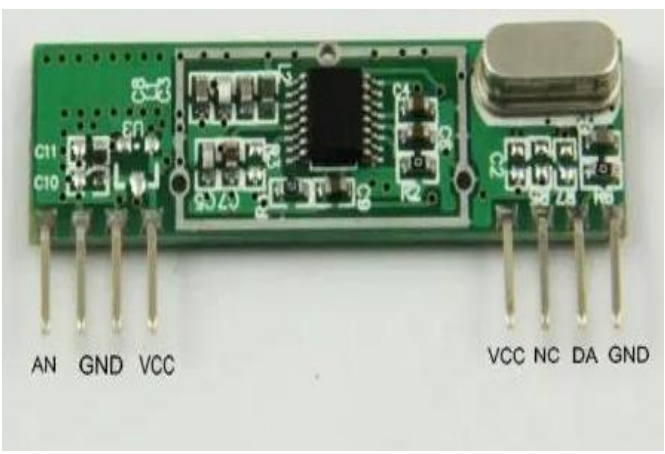

(b)

A buzzer is a sound generating system that is sometimes used. When the button on the RF remote is pressed, the buzzer is activated in case the stick is lost. The vibration engine, a mechanical unit, is used for vibration generation. When the moisture sensor senses the presence of water in the path of blind people, it is activated.

\subsection{Working Principle}

The input consists of an unbearable sensing element that is capable of sensing the obstacles ahead of it at a distance of up to $50 \mathrm{~cm}$. It is interfaced to the Arduino, that determines if an obstacle is just too about to the cane and triggers the output if it is. HC-SR04 ultrasonic sensor is used. If the obstacle is between 0-50 cm, it will notify the person with buzzer sound. The water circuit consists of two probes and $1 \mathrm{M} \Omega$ resistor. Whenever the probe touches the water, it gets short circuited and aware the person with the aid of buzzer to notify that there is water in the surface.

The stick finder circuit encompasses $433 \mathrm{MHz}$, RF Transmitter and RF Receiver. There are two different circuits for transmitter and receiver. The RF transmitter will be connected with push button which will act as a keypad to send a signal to the receiver. The RF receiver will be connected with the main circuit where the program will be dumped for giving output signal to notify the person about the stick location with the help of buzzer. IC 7805 voltage regulator is used to maintain the constant $5 \mathrm{v}$ voltage for the circuit. The created blind stick alerts the user via a vocal sound from a speaker on the stick to various obstacles. The stick can also sense damp and moist surfaces and provide the user with a vibratory warning. A simple button on the stick would do the job of sending a message to a blind person's acquaintances. A remote with a button is given to assist the user if a stick is lost, which makes a buzzer sound on the stick when pushed.

\section{Hardware Implementation and Results}

The proposed smart blind stick developed can scan the surroundings for various obstacles of different sizes and raise appropriate auditory and vibratory alerts. It can detect both damp and wet surfaces and can alert the user. The proposed prototype has been effective at spotting various obstacles of different sizes lying in the path of the user with great consistency; it was able to send SMS to his acquaintances with accurate coordinates of the user. Also, it has been quickly locatable when misplaced using the RF remote control. The RF module (Transmitter and Receiver) are able to communicate effectively with-in a range of 100m. The development circuit diagram for various stages of detection is shown in Fig. $6 \&$ 7. The distance between the obstacles was noted in the serial monitor.

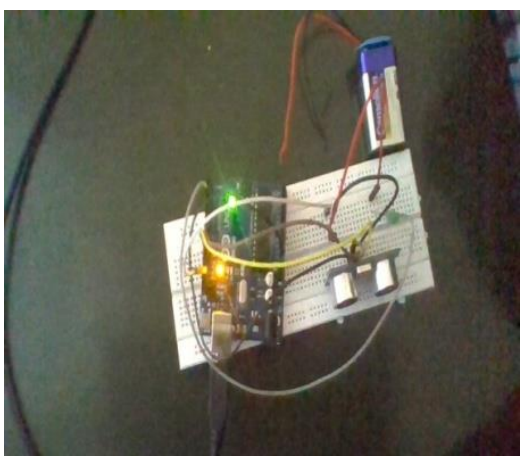

(a)

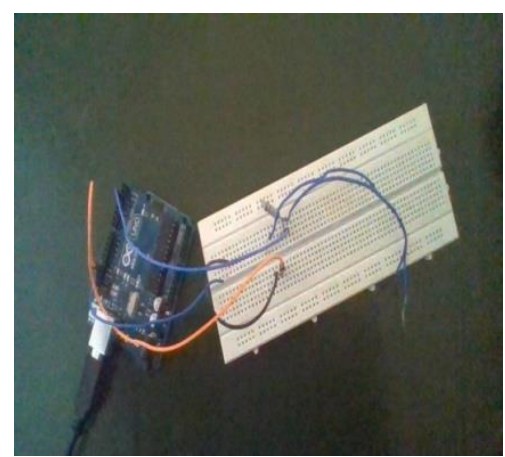

(b)

Figure 6. Hardware model a) Obstacle Detection b) Water Detection 
Fig. 7(a,b) shows the hardware model for RF Transmitter and Receiver. The data pin in RF receiver circuit is connected with RC filter is given to the Uno board. If this button is pressed, RF Receiver will provide ADC output voltage continuously. This reiteration can't be ascertained once the button isn't thumbed. It tends to code the Arduino to ascertain for consequent noticeable values whether that button is thumbed (Garikipati, 2021). This enables, a visually impaired person can able to track his walking stick.

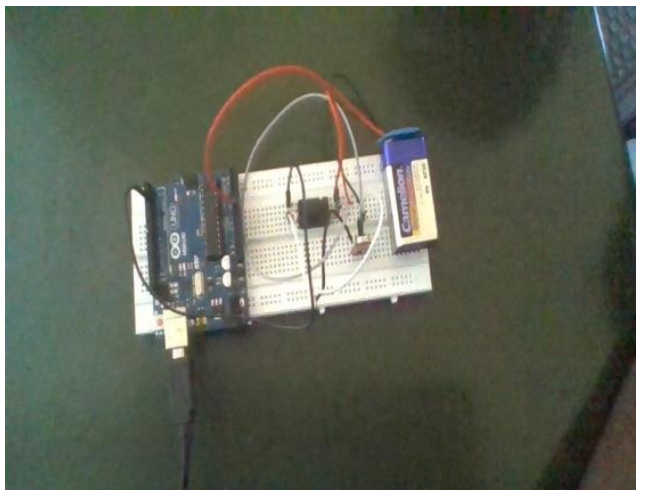

(a)

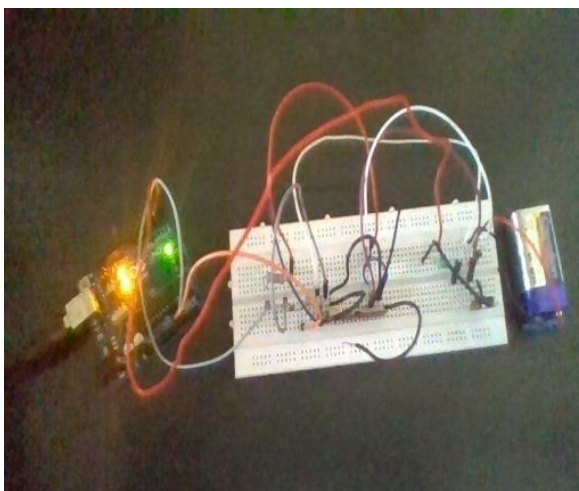

(b)

Figure 7. Hardware model for a) RF Transmitter b) RF Receiver

The transmitter and receiver signal output was monitored in the serial monitor. When the remote is pressed, it will provide remote pressed otherwise, it will display as 0 remote pressed. The entire circuit diagram for the proposed model of the electronic blind walking stick is shown in Fig. 8.

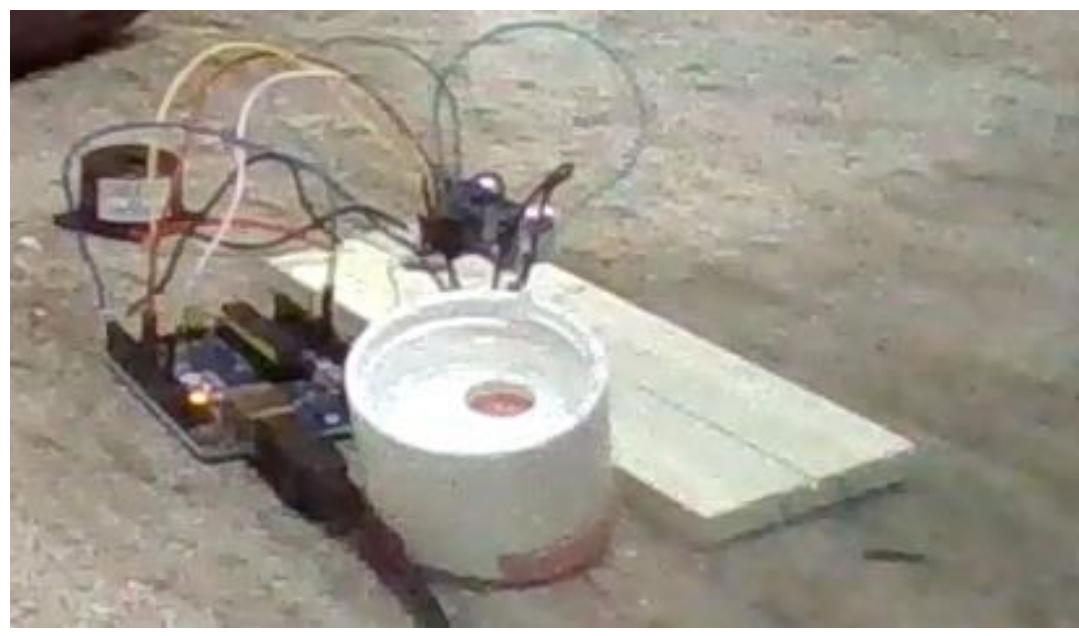

Figure 8. Proposed walking stick for Blind People

An Arduino Uno is employed to oversight all of the sensors used. The entire board is supplied with a battery of $9 \mathrm{~V}$ that is synchronized to $+5 \mathrm{~V}$ employing IC 7805 regulator. IC 7805 voltage regulator will disable all the fluctuations in the voltage source and maintain constant voltage to the circuit. It contains 3 pins namely input, ground and output. The data pin of the receiver associate with a RC filter to reduce harmonics in the transmitted signals. The supersonic sensing element is supplied with $5 \mathrm{~V}$ and the pins of trigger and Echo is connected to Arduino Uno pin of 3 and 2. To browse the signal from an RF receiver, ADC pin A0 is used. The output of the board is provided by the Buzzer linked to pin 12 . The resistor of $10 \mathrm{k} \Omega$ will be connected across $5 \mathrm{v}$ battery source. The two probes are connected across $10 \mathrm{k} \Omega$ resistor. When the probe touches the water; it will make the circuit to expose with the water. The resistor $4.7 \mathrm{k} \Omega$ will be connected across ground and data pin of the receiver. The two data pins are shorted and connected to the $4.7 \mathrm{k} \Omega$ resistor. The two ground pins of the receiver are shorted and connected to the ground. The output pin of buzzer is connected to the pin 2 and the ground. The RC filter is modelled with the resistor of $4.7 \mathrm{k} \Omega$ and the capacitor of $1 \mathrm{nf}$ for receiver circuit. The prototype model of the electronic blind walking stick is shown in Fig. 9. 


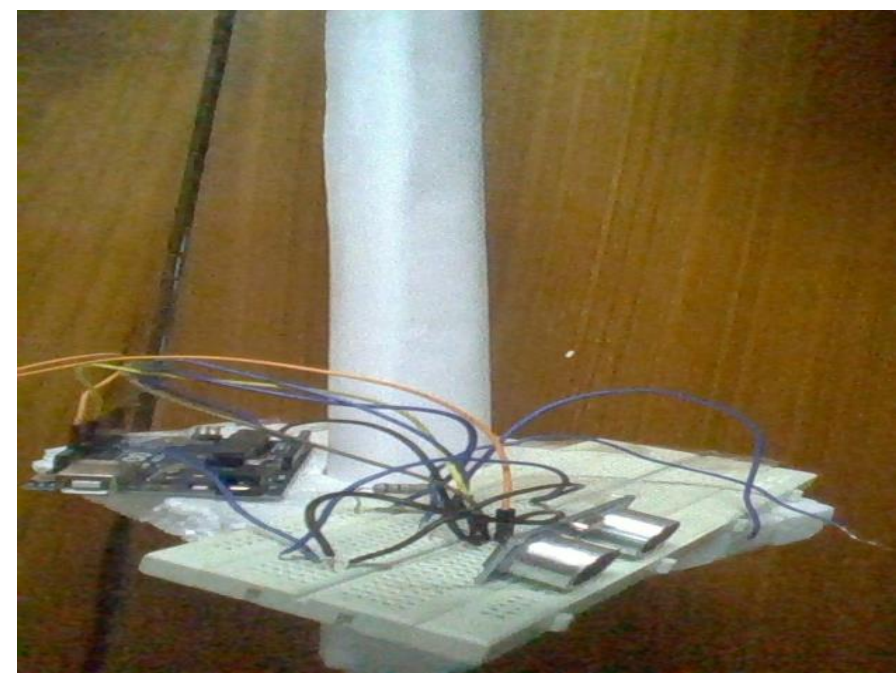

Figure 9. Prototype model of smart walking stick

The stick is successfully desegregated to detect obstacles using ultrasonic sensor, water sensing using water circuit and stick finder using RF transmitter and RF Receiver modules. The complete prototype was successfully developed and implemented to support blind people by recognizing obstacles in front of them.

\section{Conclusion}

The proposed smart walking stick reduces the burden faced by the blind people with obstacle detection, water detection and stick finder. This stick is proven as a cost effective and trouble free one to carry which will help every person to use with ease. The proposed architecture will assist the blind people to walk from one location to another without depending on other's help. This proposed stick will guarantee them for safety and assistance. The hitch obtained from the proposed model will assist the blind people as a very good navigational and directional aid also provides the path notification and the environment recognition. This stick is designed with highly sensitive sensors thus improves its design also reduces the space occupied by the stick. This stick is made with carbon material which reduces its weight also flexible to use. This work can be elongated to come up with voice output for the blind to understand the alert in the place of buzzer by distinguishing the many types of obstacles.

\section{References}

1. Agrawal, M.P., Gupta, A.R. (2018) Smart Stick for the Blind and Visually Impaired People, Second International Conference on Inventive Communication and Computational Technologies, pp. 542-545.

2. Al Barrm, O.B., Vinouth, J.(2014) 3D ultrasonic stick for blind", International Journal of Latest Trends in Engineering \& Technology.3.

3. Aroulanandam VV, Latchoumi TP, Balamurugan K, Yookesh TL. (2020) Improving the Energy Efficiency in Mobile Ad-Hoc Network Using Learning-Based Routing, Revue d'Intelligence Artificielle, Vol 34(3), pp. 337-343, 2020.

4. Balamurugan K. (2020) Metrological changes in surface profile, chip, and temperature on end milling of M2HSS die steel. International Journal of Machining and Machinability of Materials, 22(6):pp. 443-453.

5. Balamurugan K and Uthayakumar M, (2017) Preparation And Machining Studies Of Lapo4 Y2o3 Ceramic Matrix Composite, http://hdl.handle.net/10603/166221.

6. Balamurugan K, Uthayakumar M, Sankar S, Hareesh US, Warrier KG. (2020) Process optimisation and exhibiting correlation in the exploitable variable of AWJM. International Journal of Materials and Product Technology, 61(1), pp.16-33.

7. Chinnamahammad bhasha A, and Balamurugan, K. (2020) Fracture analysis of fuselage wing joint developed by aerodynamic structural materials." Materials Today: Proceedings, Vol.38, pp. 2555-2562.

8. Garikipati P, and Balamurugan K. (2021) Abrasive Water Jet Machining Studies on AlSi $7+63 \%$ SiC Hybrid Composite. InAdvances in Industrial Automation and Smart Manufacturing, pp. 743-751, Springer, Singapore.

9. Gayathri, G., Vishnupriya, M., Nandhini, R., Banupriya, M.M. (2014) Smart walking stick for visually impaired", International Journal of Engineering and Computer Science,.3(3):4057-4061, 2014. 
10. Gupta, S., Sharma, I., Tiwari, A., Chitranshi, G. (2015) Advanced guide cane for the visually impaired people", $1^{\text {st }}$ International Conference on Next Generation Computing Technologies (NGCT), pp.452-455.

11. Jaya Lakshmi, A., Swetha, J., Swamy, G. N. (2019) Enhanced Multi-Transmitter Based Channel Selection Matching 3 System for Cognitive Radio Ad Hoc Network”, IMPACT: International Journal of Computational Sciences and Information Technology (IMPACT: IJCSIT ), 1( 1): 1-12

12. Latchoumi TP, Reddy MS, Balamurugan K. (2020) Applied Machine Learning Predictive Analytics to SQL Injection Attack Detection and Prevention. European Journal of Molecular \& Clinical Medicine.;7(02), pp. 3543-3553.

13. Manikanta K, T.Siva Sankara Phani \& A.Pravin. (2018) Implementation and design of Smart Blind Stick for obstacle detection \& navigation System",2018.

14. Nadia Nowshin, Sakib Shadman, Saha Joy (2017) Sarker Aninda, Islam Md Minhajul, “An Intelligent Walking Stick for the Visually Impaired People", International Journal of Online \& Biomedical Engineering . 13(11).

15. Navdeep Kaur, Harmeet Singh. (2019) A Survey on Recent Work in Hybrid FSO/RF Communication Link”, International Journal of Electronics, Communication \& Instrumentation Engineering Research and Development (IJECIERD) 9(1) pp, 25-32.

16. Olanrewaju, R.F., Radzi, M.L.A.M., Rehab. (2019) Walk:Intelligent walking stick for visually impaired subjects", IEEE $4^{\text {th }}$ International Conference in Smart Instrumentation, Measurement \& Application:pp. 1-4,2017.

17. Patil Nagesh Umakant, Dr. Sandeep Tiwari \& Dr. Chandrakant Kulkarni. (2019) Solar Operated Agribot For Green House Farming”, International Journal of Mechanical and Production Engineering Research and Development (IJMPERD), 9 (5): 643-656.

18. Pavan MV, Balamurugan K, Balamurugan P. (2020) Compressive test Fractured Surface analysis on PLA-Cu composite filament printed at different FDM conditions. InIOP Conference Series: Materials Science and Engineering, Vol. 988,pp. 012019. IOP Publishing.

19. Radhika R, Payal G, Rakshitha S, Rampur Srinath.(2016) Implementation of Smart Stick for Obstacle Detection \& Navigation", International Journal of Latest Research in Engineering \& Technology , 02, 45-50.

20. Rajesh Kannan., V. \& Mariyammal, A. (2019) An EEG-Based Brain Controlled Design with an Itinerant Robot”, BEST: International Journal of Management, Information Technology and Engineering (BEST: IJMITE), 4 (4): pp, 107-112.

21. Swain, K.B., Patnaik, R.K., Pal, S., Rajeswari. R. (2017) A.Mishra and C.Dash, "Arduino based automated STICK GUIDE for visually impaired person", IEEE International Conference on Smart Technologies \& Management for Computing,Communication, Controls, Energy and Materials , : 407410.

22. Vaibhav Shah, Sahil Shah, Jay Shah \& Prithvish Mamtora Anti-Theft Home Security System”, International Journal of Electronics and Communication Engineering (IJECE), 2, (4):113-118.

23. Virendra K. Verma, D. K. Mishra \& R. S. Gamad.(2019) A Comparative Anlysis of Frequency Synthesizers ", International Journal of Electronics and Communication Engineering (IJECE), 2 (4): pp, 95-104

24. Ueda, T. A., L.V.De Araujo. (2014) Virtual walking stick Mobile application to assist visually impaired people to walking safely", International Conference on universal access in Human-Computer Interaction, pp.803-813. 